\title{
CFD Analysis of Fluid Film of Liquid Lubricated Cylindrical Journal Bearing
}

\author{
Debaprava Das ${ }^{1}$, Dr Ritesh Kumar Dewangan² \\ ${ }^{1}$ Research Scholar, Department of Mechanical Engineering, RCET Raipur, India. \\ ${ }^{2}$ Associate Professor, Department of Mechanical Engineering, RCET Raipur, India.
}

\begin{abstract}
The current research work deal with the fluid structural and computation fluid dynamic analysis of hydrostatic bearing fluid film by using ANSYS software. Journal bearing consist of different grade of oil or fluid for lubrication purpose and here we have taken two different grade of SAE 20 and SAE 40 liquid. The Reynolds equation, which is a function of film thickness, is satisfied by the pressure in the oil film in a fluid film bearing. The current work based on the calculation of deformation of bearing due to loading condition by using length to diameter ratio (L/D) [1] and different eccentricity ratio. The ratio of length and diameter is consider as 0.5 and the eccentricity is vary from 0 to 1.0 with interval of 0.2 and start with 0.3 as $0.3,0.5,0.7$ and 0.9 the lubricant SAE $20 \&$ SAE 40 is consider for analysis with same boundary condition and final output is compared for both liquid lubricant. The CFD analysis and structure analysis is performed by using ANSYS software and first we apply the CFD simulation and the output is linked with structure workbench to apply the pressures on bearing.
\end{abstract}

Keywords: CFD Computational fluid Dynamic, FSI fluid structure interaction, AR aspect ratio

\section{INTRODUCTION}

Because of their higher durability and load carrying capability, hydrodynamic journal bearings have been widely utilised to support high-speed rotating machinery such as turbines and compressors. As a result, bearings are critical machine components for improving the quality of rotating machinery. Because the performance and characteristics of high-speed, hydrodynamic journal bearings operating in both laminar and turbulent flow regimes are governed by a number of bearing parameters, bearing designers typically use a trial-and-error method using many design charts obtained from the bearing characteristic analysis to select the design variables within constraints.

This method, on the other hand, simply ensures that acceptable solutions are produced, not always the best answers. Furthermore, even if the bearing designers are successful in obtaining optimal solutions using this method, a significant amount of time and money will be required to finish the optimum design of high-speed journal bearings.

\section{PROBLEM IDENTIFICATION:}

The hydrostatic general bearing is one of the bought out parts which is already define for specific load and RPM with some specific parameters so the scope of work is to limited to lubricant which play an important role. Here we have taken two lubricant to identify the performance of both lubricant and find out the interaction of fluid film with the elastic behaviour of bearing. SAE20 and SAE40 lubricant is consider for analysis in ansys software by using CFD and structure work bench with different eccentricity ratio.

\section{Parameters of bearing:}

\begin{tabular}{|l|l|}
\hline Diameter of journal D & $100 \mathrm{~mm}$ \\
\hline Journal length L & 50 \\
\hline Ratio (L/D) & 0.5 \\
\hline Eccentricity mm e & $\varepsilon \times \mathrm{C}$ \\
\hline Radial clearance C & $0.145 \mathrm{~mm}$ \\
\hline Eccentricity ratio $\varepsilon$ & 0.3 to 0.9 \\
\hline
\end{tabular}

Eccentricity calculation table on $\mathrm{L} / \mathrm{D}$ at 0.5 :

\begin{tabular}{|c|c|c|c|}
\hline S No. & $\boldsymbol{\varepsilon}$ & $\mathbf{C}$ & $\mathrm{e}=\varepsilon \times \mathrm{C}$ \\
\hline 1 & 0.3 & 0.145 & 0.0435 \\
\hline 2 & 0.5 & 0.145 & 0.0725 \\
\hline 3 & 0.7 & 0.145 & 0.1015 \\
\hline 4 & 0.9 & 0.145 & 0.1305 \\
\hline
\end{tabular}

Analytical calculation of stress and force induced in bearing

$$
\begin{gathered}
\mathrm{F}=\frac{\pi^{2} D^{2} L N}{30 * C} \mu \\
\sigma=\frac{F}{A} \mathrm{~N} / \mathrm{mm}^{2}
\end{gathered}
$$

where

$$
\begin{aligned}
& F=\text { force } N \\
& D=\text { diameter of journal bearing } \\
& L=\text { length of bearing } \\
& N=\text { speed } \\
& \mu=\text { coefficient of friction }
\end{aligned}
$$




\section{METHODOLOGY}

\section{CFD Modelling and analysis of bearing}

In order to simulate the bearing in ansys environment first of all a graphical model of journal bearing is to be developed or design with specified parameters in geometry tools then its browsed for the analysis. The typical analysis sequence in the CFD tools is given below.

- Geometry

- Mesh

- Setup

- Solution

- Result

\section{Geometry \& meshing of journal bearing}

The geometry is created by sketching of two-dimensional profile of bearing inner ring and then its revolve around the center of the bearing. A thin surface of fluid film is also created to define the geometry of fluid film. After modelling of bearing it required to mesh and divide whole geometry into small nodes and elements.
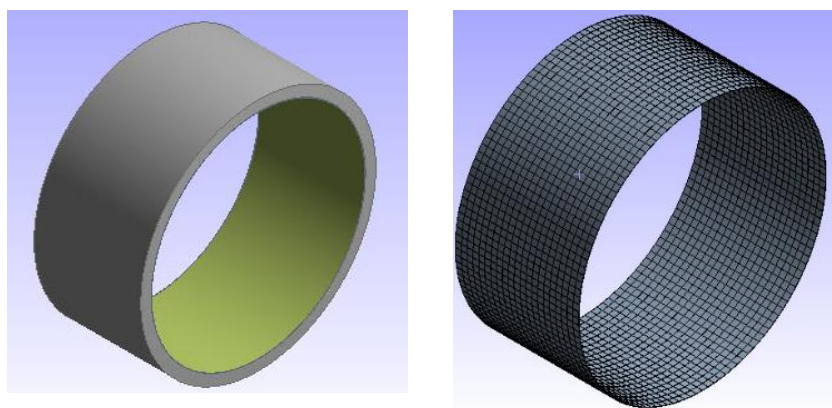

\section{Setup \& boundary condition}

A thin geometry of surface is used to represent the profile of surface and based on the geometry inlet and outlet is defined to identify the flow of liquid and pressure based solver is used to simulate the analysis.

\section{Property of fluid film}

\begin{tabular}{|l|c|c|c|}
\hline \multicolumn{1}{|c|}{ PROPERTIES } & SAE20 & SAE40 & $\begin{array}{c}\text { BABBIT } \\
\text { MATERIAL }\end{array}$ \\
\hline Density (kg/m3) & 872 & 887 & 0.000007272 \\
\hline $\begin{array}{l}\text { Thermal } \\
\text { conductivity (w/m-k) }\end{array}$ & 0.136 & 0.136 & $\begin{array}{c}\text { Young's } \\
\text { modulus }\end{array}$ \\
\hline $\begin{array}{l}\text { Specific heat } \\
\text { Cp(J/kg-k) }\end{array}$ & 19252.96 & 1800 & $50,000 \mathrm{MPa}$ \\
\hline Viscosity (kg/m-s) & 0.0056 & 0.0056 & Poisson's ratio \\
\hline Velocity of flow (m/s) & 10.45 & 10.45 & 0.35 \\
\hline
\end{tabular}

\section{Solution \& result of CFD and structure analysis}

After successfully run of simulation, it lead us to a result in graphical form to represent the behaviour of bearing under loading condition.

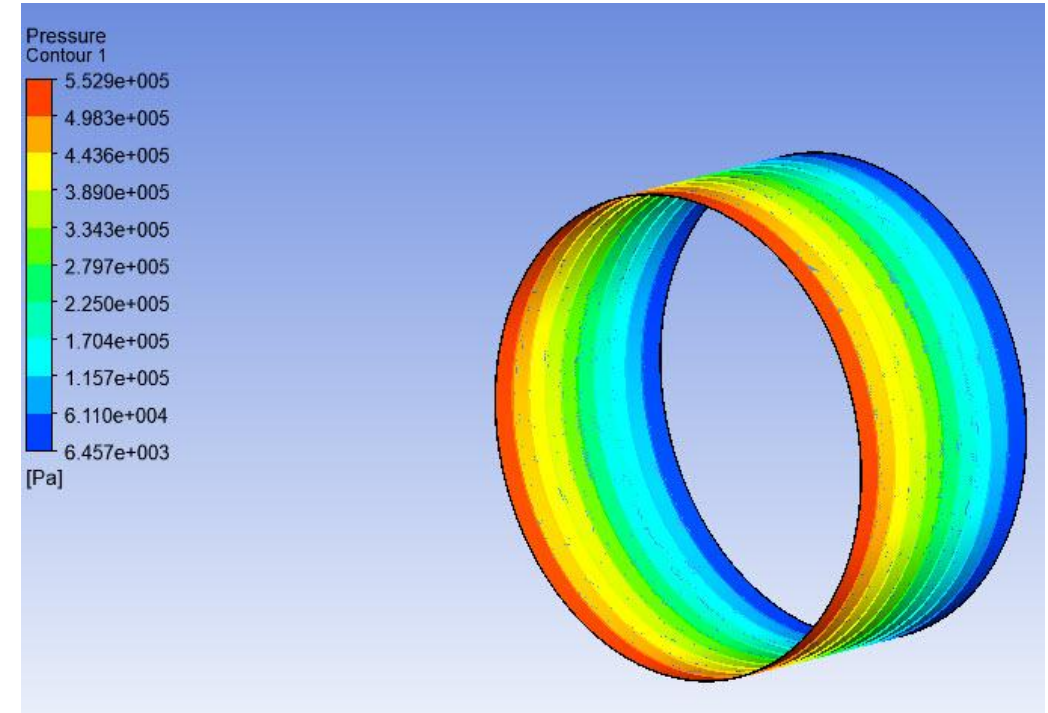

The CFD result is hyperlink with structure analysis workbench to apply the required pressure in the bearing. 


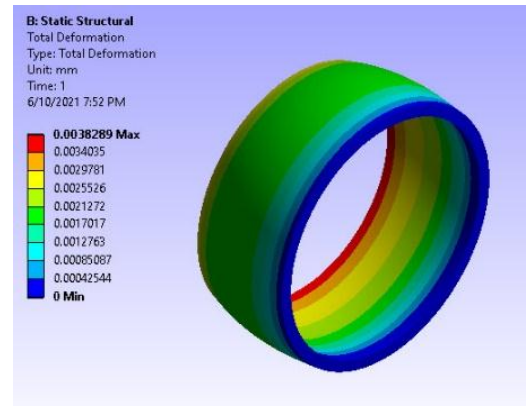

Total deformation

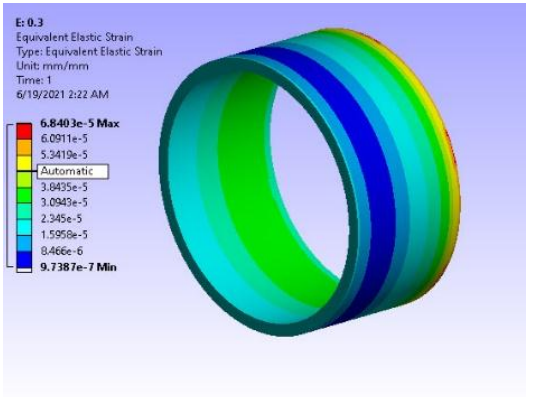

Elastic strain

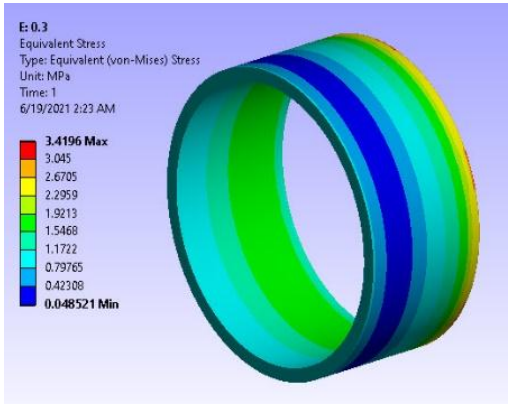

Stress distribution

\section{Result of of SAE 20 and SAE 40 fluid film}
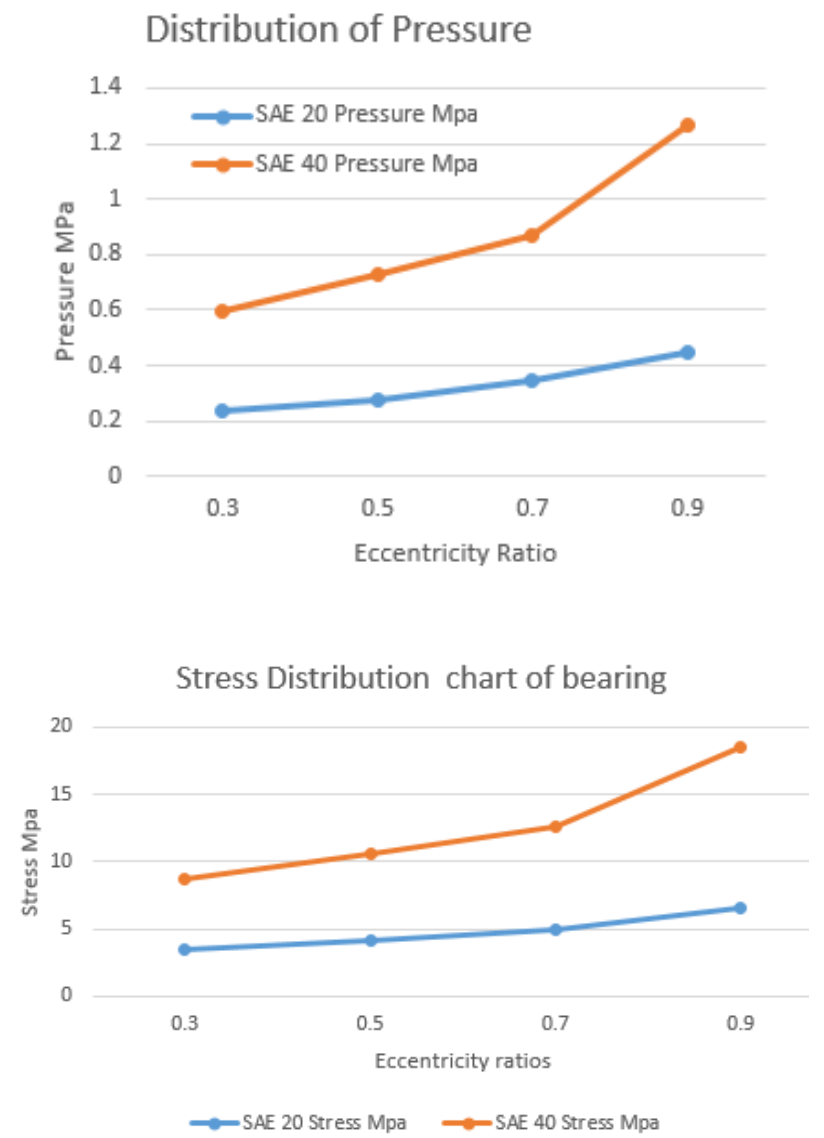

The distribution of stress pressure deformation and strain of bearing is given here to identify the nature of fluid film and bearing under loading condition.

\section{CONCLUSION}

Based on the graph and data furnished in result section we concluded that the nature of graph for all cases is almost similar and small variation is found in case of eccentricity ratio of 0.9 for both liquids, its show some difference nature and vale is higher as compare to rest eccentricity ratio.so that we can say that the value of stress and other parameter is gradually

\section{Deformation of Bearing}
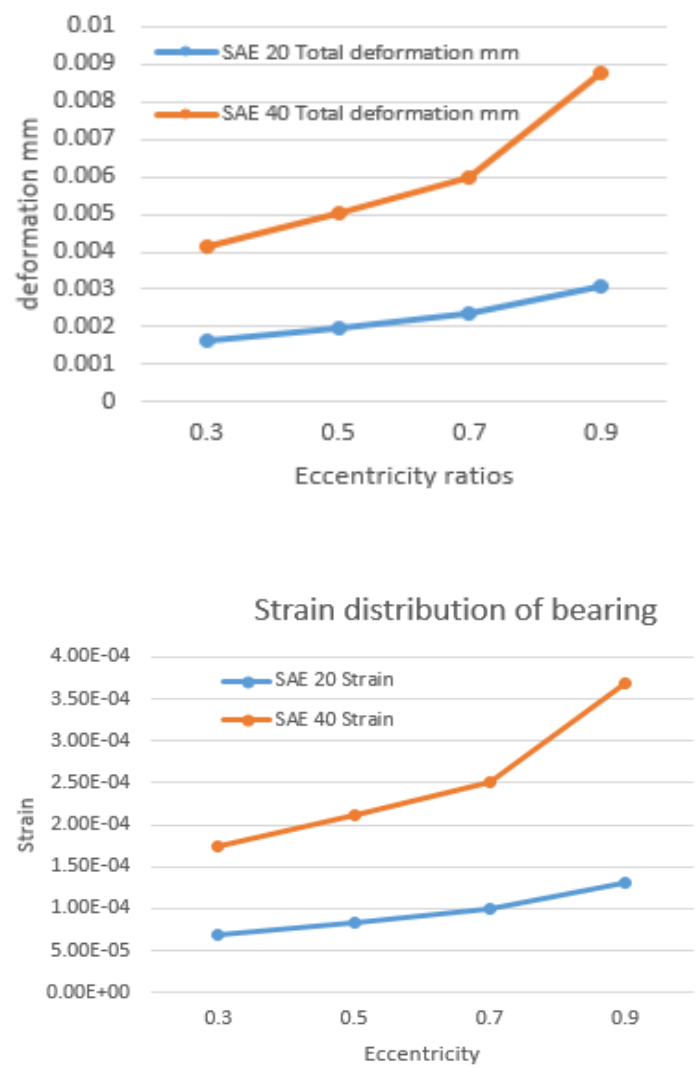

increases and it becomes higher at the eccentricity 0.9.The bearing has a significant amount of distortion, as can be seen. When these data are compared, SAE 20 oil with an eccentricity ratio of 0.3 is the optimum choice for journal bearings.

\section{REFERENCES}

[1] K Prasad et al, "Fluid Structure Interaction of Liquid Lubricated Cylindrical Journal Bearing using CFD", IJIRSET, Vol.5, issue 3, march 2016.

[2] MahenderJanagam, D. Prasuna Lilly Florence and Dr. P. H V SeshaTalpaSai, Fluid Structure Interaction On 
International Journal of Applied Engineering Research ISSN 0973-4562 Volume 16, Number 7 (2021) pp. 607-610

(C) Research India Publications. https://dx.doi.org/10.37622/IJAER/16.7.2021.607-610

Journal Bearings At Different L/D And Eccentricity Ratios, International Journal of Science, Engineering and Technology Research (IJSETR), Volume 4, Issue 11, November 2015.

[3] B. S. Shenoy, R. S. Pai, D. S. Rao, R. Pai,Elastohydrodynamic lubrication analysis of full 360 journal bearing using CFD and FSI techniques, World Journal of Modeling and Simulation,ISSN 1 746-7233, Vol. 5 (2009) No. 4, pp. 315-320.

[4] PriyankaTiwari, Veerendra Kumar, Analysis of Hydrodynamic Journal Bearing Using CFD and FSI Technique, www.ijert.org, Volume/Issue:Vol. 3 - Issue 7 (July - 2014), e-ISSN: 2278-0181.

[5] Samuel A. McKee, Journal-Bearing Design As Related To Maximum Loads, Speeds, And Operating Temperatures, Part of Journal of Research of the National Bureau of Standards, Volume 19, October 1937.

[6] S. Sharma, D. Hargreaves, W. Scott, Journal bearing performance and metrology issues, Journal of Achievements in Materials and Manufacturing Engineering

[7] P.C. Mishra, Analysis of a Rough Elliptic Bore Journal Bearing using Expectancy Model of Roughness Characterization.

[8] P. Allaire, J. Nicholas, E. Gunter. Systems of Finite Elements for finite bearings. ASME Journal of Lubrication, Technology, 1972, (99): 187-197.

[9] P. Allaire, J. Nicholas, E. Gunter. Systems of Finite Elements for finite bearings. ASME Journal of Lubrication Technology, 1972, (99): 187-197.

[10] Proc. of ASME/STLE International Joint Tribology Conference, San Diego, California, US, 2007, 1-3. IJTC'07, IJTC44479.

[11] J. Booker, K. Huebner. Application of Finite Element Methods to Lubrication: an Engineering Approach. ASME Journal of Lubrication Technology, 1972, (94): 313-323.

[12] P. Brajdic-Mitidieri, A. Gosman, et al. CFD Analysis of a Low Friction Pocketed Pad Bearing. ASME Journal of Tribology, 2005,127(4): 803-812.

[13] P. Chen, E. Hahn. Use of Computational Fluid Dynamics in Hydrodynamic Lubrication. proceedings of Institute of Mechanical Engineers: Part J, Journal of Engineering Tribology, 1998, (6): 427-435.

[14] B. George, W. Fred. Analytical Derivation and Experimental Evaluation of Short Bearing $\mathrm{Z}$ approximation for Full Journal Bearings. NACA TN, 1953, 1199-1230.

[15] Z. Guo, H. Toshio, R. Gordon. Application of CFD Analysis for Rotating Machinery Part1: zy urodynamic, Hydrostatic Bearings and Squeeze Film Damper. Journal of Engineering for Gas Turbines and Power,
2005, 127(2): 445-451.

[16] M. Reddi. Finite-Element Solution of the Incompressible Lubrication Problem. ASME Journal of Lubrication Technology, 1969,91(3): 524-533. 